\title{
Do the primary and secondary intensions of phenomenal concepts coincide in all worlds?
}

\author{
Robert SCHROER \\ Dept. of Philosophy, University of Minnesota at Duluth, email: rschroer@d.umn.edu
}

\begin{abstract}
A slew of conceivability arguments have been given against Physicalism. Many Physicalists try to undermine these arguments by offering accounts of phenomenal concepts that explain how there can be an epistemic gap, but not an ontological gap, between the phenomenal and the physical. Some complain, however, that such accounts fail to do justice to the nature of our introspective grasp of phenomenal properties. A particularly influential version of this complaint comes from David Chalmers (1996, 2003), who claims, in opposition to the accounts of phenomenal concepts described above, that phenomenal concepts have primary and secondary intensions that coincide in all worlds.

In this paper, I construct an argument that casts doubt upon Chalmers' claim. At the heart of this argument is an idea that Chalmers shows some affinity for: namely, that introspection doesn't reveal whether phenomenal properties are fundamental properties or whether they are derived from more basic protophenomenal properties. I argue that this claim implies that the primary and secondary intensions of our phenomenal concepts do not coincide in all worlds. In this way, I show that a plausible idea about the powers of introspection - an idea that Chalmers himself is drawn to - is a reason for rejecting the claim that phenomenal concepts have primary and secondary intensions that coincide in all worlds.
\end{abstract}

\section{The Phenomenal Concept Strategy}

Do the primary and secondary intensions of phenomenal concepts coincide in all worlds?

I will argue that the answer is no. Before giving my argument, however, I need to lay out some background information. There are well-known arguments against Physicalism: the knowledge argument (see Jackson 1982), the explanatory gap (see Levine 1983, 2001), and various conceivability arguments (see, in particular, Kripke 1980 and Chalmers 1996). Following the lead of Chalmers (2002), I will understand all of these arguments as initially pointing to an epistemic gap between the phenomenal and the physical—at the most basic level, each highlights a failure of a priori entailment of phenomenal truths from physical/functional truths. ${ }^{1}$ On the basis of this epistemic gap, most of these

\footnotetext{
${ }^{1}$ By "the phenomenal", I am referring to the "what it's like" aspect of experience. I will refer to the properties that are responsible for this aspect of experience as "phenomenal properties". Examples of phenomenal properties would include the felt redness one is
} 
arguments conclude that there is also an ontological gap between the phenomenal and the physical/functional. $^{2}$

Following the lead of Chalmers (1996), we can distinguish two general kinds of responses that Physicalists give to such arguments. "Type-A Materialists" deny the opening premise of these arguments by claiming that phenomenal truths are, in fact, $a$ priori entailed by physical/functional truths. "Type-B Materialists", in contrast, accept the opening premise of these arguments - they accept that physical/functional truths do not a priori entail phenomenal truths_- but then deny that this epistemic gap entails the existence of an ontological gap between the physical/functional and the phenomenal. In advancing the latter position, many Type-B Materialists focus upon our "phenomenal concepts"-i.e. concepts that are directly applied to phenomenal experience on the basis of introspection. Type-B Materialists drawn to this defensive strategy maintain that there is something about phenomenal concepts that explains why there is an epistemic gap, but not an ontological gap, between the phenomenal and the physical. I will follow the lead of Daniel Stoljar (2005) and call this particular Type-B Materialist strategy "The Phenomenal Concept Strategy", or "PCS" for short.

PCS has dominated the recent literature on phenomenal properties. ${ }^{3}$ A recurring complaint against this strategy is that it generates accounts of phenomenal concepts that fail to do justice to the nature of our introspective grasp of phenomenal properties. Consider, for example, an early and influential version of PCS developed by Brian Loar

aware of when looking at a ripe tomato and the painfulness one is aware of when stepping upon a tack.

${ }^{2}$ Levine's position on this issue is a bit more complicated; I will not discuss it here.

${ }^{3}$ For a recent collection on the topic, see Alter and Walter 2007. For an interesting critical review of PCS, see Chalmers 2007. 
(1990) which identifies phenomenal concepts with type-demonstrative concepts that directly pick out properties of experiences from an introspective perspective. As I interpret it, Loar's account maintains that a phenomenal concept provides a thin characterization of its referent — it characterizes it simply as "that property again". As a result of its thinness, the cognitive content of this concept is not a priori deducible from a physical/functional description of the same property. The problem with Loar's account, however, is that the contents of these type-demonstrative concepts do not seem substantial enough to be plausible candidates for the contents of phenomenal concepts. What introspection "tells" us about phenomenal properties seems richer than the content you would get from an act of demonstrative pointing that characterizes its referent merely as "that property again". 5

Motivated by the shortcomings of Loar's account on this front, Janet Levin (2002, 2007) has developed a version of PCS where phenomenal concepts are hybrid concepts that are part recognitional and part causal-functional. Phenomenal concepts of phenomenal color, for instance, contain "relational descriptions of quality spaces with 'slots' reserved for type-demonstratives that are normally acquired by having the experiences in question" (Levin 2007, 98). Under this account, the contents of phenomenal concepts are more substantial than they are under Loar's account. A phenomenal concept of a phenomenal color does more than just characterize its referent

\footnotetext{
${ }^{4}$ In interpreting Loar's position along these lines, I am following the lead of Levin 2007. Others, in contrast, treat Loar's claim that phenomenal properties serve "as their own mode of presentation" as implying that phenomenal concepts provide a "thick" characterization of their referents in virtue of containing those referents as constituents. (For a good discussion of the latter interpretation of Loar, see Papineau 2002.) ${ }^{5}$ For versions of this complaint against Loar, see Levine 2001, Chalmers 2007, and Levin 2007.
} 
as "that property again"; it also provides a characterization of the similarity space that this phenomenal color stands in relative to other phenomenal colors.

Motivated by the same concern about Loar's account, I've developed yet another version of PCS where a phenomenal concept characterizes the internal complexity of a given phenomenal color by demonstratively identifying the component elements of that phenomenal color - e.g. its saturation, lightness, and saturation - and then describing how much of each of these elements is present in the phenomenal color in question (see Schroer 2010). Phenomenal orange, for example, is introspectively characterized as containing such-and-such level of that element (demonstratively identified saturation), such-and-such level of that other element (demonstratively identified lightness), and as having another component element (hue) that, in turn, is composed of $50 \%$ of that element (demonstratively identified reddishness) and 50\% of that element (demonstratively identified yellowishness). Like the accounts of Loar and Levin, my account uses demonstratives to explain the failure of a priori entailment from physical facts to phenomenal facts. Unlike those other accounts, however, according to my account phenomenal concepts provide a more substantial characterization of the intrinsic nature of the phenomenal colors - they provide a characterization of some of the internal complexity of those properties.

Despite our attempts to retain the key idea of Loar's account while also making the content of phenomenal concepts more substantial, some would claim that Levin's account and my account still fail to do full justice to the nature of our introspective grasp of phenomenal properties. In the next section, I lay out an influential formulation of this kind of objection from David Chalmers. 
II. The Primary and Secondary Intensions of Phenomenal Concepts

David Chalmers $(1996,2003)$ maintains that our introspective grasp of phenomenal properties is substantial enough to ensure that the primary and secondary intensions of our phenomenal concepts coincide in all worlds. To understand this claim, and to see how it serves as an objection to PCS, we first need to review the basics of Chalmers' "two-dimensional framework".

According to the two-dimensional framework, a concept has two intensions (or "meanings"). To start with, it has a primary (or "epistemic") intension that determines the extension of that concept in a given world where that world is considered as actual. According to Chalmers, the analysis of a concept's primary intension "... is an a priori enterprise, as it involves questions about what our concepts would refer to if the actual world had turned out various ways" $(1996,59) .{ }^{6}$ In addition to its primary intension, a concept also has a secondary (or "subjunctive") intension that determines its extension in a given world where that world is considered as counterfactual. The extension of the secondary intension of a rigid concept in a given world - or, more specifically, the secondary intension of a natural kind concept, which is the kind of rigid concept that we're focusing upon-is determined by first taking the extension of its primary intension

\footnotetext{
${ }^{6}$ For a contrasting account where the analysis of the primary intension of a concept is not an a priori enterprise, see Stalnaker 2002. (For another statement of the same basic idea, see Levin 2007.)
} 
in the actual world and then "rigidifying" so that the same extension is picked out by the secondary intension in all worlds $(1996,59) .^{7}$

To see this framework at work, let's apply it to a specific concept: WATER. This concept has a primary intension that picks out whatever happens to be the "watery substance" in each possible world. To put it another way, in determining the extension of the primary intension of WATER, we treat each possible world as though it were the actual world and pick out whatever is "the dominant clear, drinkable liquid in the oceans and lakes" $(1996,57)$ in that world. Since the primary intension of WATER picks out its extension via relatively superficial features of that extension - and not in virtue of its microphysical essence - the extension of the primary intension of WATER will change from world to world. (In a world where the local "watery substance" was XYZ, for instance, the primary intension of WATER would pick out XYZ.) To express the same idea using some helpful terminology from Chalmers (2003), WATER has a primary intension that is not "epistemically rigid" in that it does not eliminate all the epistemic possibility with regard to its extension. Since WATER is a natural kind concept, however, the secondary intension of WATER takes whatever happens to be the watery substance in the actual world - i.e. H2O — and then "rigidifies" so that the same extension is picked out by that intension in all worlds. In this manner, the extension of the secondary intension of WATER in a given world is determined by treating the relevant world as counterfactual, and not as actual.

\footnotetext{
${ }^{7}$ To be clear, Chalmers $(2010,150)$ explores the possibility that "mass" - a natural kind term - is a non-rigid designator with a secondary intension that picks out different properties in different worlds. I'll ignore this complication in what follows.
} 
With the basics of the two-dimensional framework in place, let's return to the Chalmers' claim that the primary and secondary intensions of phenomenal concepts coincide. ${ }^{8}$ In making this claim, Chalmers is saying that phenomenal concepts are more like the concept SQUARE than they are like the concept WATER. The primary intension of SQUARE — an intension that would be a priori analyzed along the lines of "a closed, four-sided figure"-picks out the same extension in every world. (To again adopt the terminology of Chalmers (2003), this particular primary intension is "epistemically rigid". ${ }^{9}$ ) Since the secondary intension of this concept picks out closed, four-sided figures in the actual world and is subsequently "rigidified", it follows that the primary and secondary intensions of SQUARE coincide in all worlds. Chalmers maintains that the same holds true of phenomenal concepts: their primary intensions are epistemically rigid - they pick out the same extensions in all worlds. Since the secondary extensions of phenomenal concepts pick out the same extensions in the actual world and are subsequently "rigidified", it follows that the primary and secondary intensions of phenomenal concepts coincide in all worlds.

Now that I've described the two-dimensional framework and Chalmers' claim that the primary and secondary intensions of phenomenal concepts coincide, let's return to the topic of PCS and the charge that it makes the contents carried by phenomenal

\footnotetext{
${ }^{8}$ It's worth noting that Chalmers (2003) makes this claim only with respect to what he calls "pure" phenomenal concepts. Pure phenomenal concepts of phenomenal properties characterize the intrinsic nature of those properties. This is in contrast to "non-pure" phenomenal concepts that characterize phenomenal properties in terms of their relations to external objects - e.g. a non-pure phenomenal concept of phenomenal red might characterize that phenomenal property as "the phenomenal property typically caused by red things".

${ }^{9}$ From some complications and possible reservations about this claim concerning the primary intension of SQUARE, see Chalmers 2012, 325-336.
} 
concepts too thin. Earlier, I explained how Levin's account and my account try to avoid this complaint by making the contents of phenomenal concepts more substantial. If, however, you accept Chalmers claim that the primary intension of a phenomenal concept eliminates all the epistemic possibilities with regard to its extension and, as a result, that the primary and secondary intensions of phenomenal concepts coincide, Levin's account and my account are both sunk. Why? Because according to our accounts, phenomenal concepts do not eliminate all the epistemic possibilities with regard to their extensions. In the case of phenomenal colors, I maintained that phenomenal concepts provide a characterization of their extensions as containing various levels of demonstratively identified elements. Such a characterization will not a priori eliminate all the epistemic possibilities regarding those extensions, for the primary intension of such a phenomenal concept will yield different extensions in different worlds in virtue of those worlds "plugging in" different entities into the demonstrative slots of the cognitive content of that concept. ${ }^{10}$

The overall dialectical situation, then, is as follows. I agree with the complaint that Loar's account of phenomenal concepts makes the contents of these concepts too thin. But I disagree that the contents of these concepts is thick enough to eliminate all the epistemic possibilities with regard to their extensions; I disagree that the primary and secondary intensions of phenomenal concepts coincide. To defend my account from Chalmers' claim, I need to generate an argument for thinking that the primary and secondary intensions of phenomenal do not coincide. Of course, an argument that

\footnotetext{
${ }^{10}$ For the record, Levin (2007) seems to embrace the claim that, under a typedemonstrative account of phenomenal concepts, the primary and secondary intensions of such concepts will coincide. I will not engage Levin's arguments for this conclusion here, although I suspect that this difference is largely terminological.
} 
undermines Chalmers' claim doesn't just aid my account; it also aids Levin's account and even Loar's account. ${ }^{11}$ Given that I think that introspection gives us a thicker grasp of phenomenal properties than Loar's account allows, and given that I think this grasp is of the internal complexity of phenomenal properties, I have independent reasons for thinking that my version of PCS is superior to that of either Loar or Levin. But I will not focus on those reasons today; instead, I will focus on the more general project of developing an argument against the claim that the primary and secondary intensions of phenomenal concepts coincide. $^{12}$

It would be good if the premises of this argument were such that most Physicalists would find them acceptable. ${ }^{13}$ It would be great if its premises were such that someone who is genuinely neutral in this debate would find them acceptable. And it would be remarkable if my argument contained premises that Chalmers himself accepts, or at least shows some affinity for. Surprisingly, I believe that such an argument can be constructed around an idea that Chalmers seemingly endorses in his discussion of Panpsychism. In the next section, I identify this idea.

III. Chalmers on the Problem of Matter and the Threat of Panpsychism

\footnotetext{
${ }^{11}$ I want to thank an anonymous referee for highlighting this point.

${ }^{12}$ For a discussion of why I think my version of PCS is preferable to those of Loar and Levin, see Schroer 2010.

${ }^{13}$ One move made on this front is to accuse Dualists (like Chalmers) of having fallen victim of the "headless woman effect"-i.e. of mistakenly inferring, from a lack of awareness of certain aspects of phenomenal properties, that they must be aware of those properties as lacking those aspects. The classic presentation of this objection is found in Armstrong 1968.
} 
The relevant idea is found in Chalmers' brief but provocative discussion of "the problem of matter". ${ }^{14}$ As Chalmers (1996) frames it, the problem of matter stems from the fact that the physical sciences provide a relational description of the objects they describe, a description in terms of their propensity to causally interact with one another. The "problem" is that such a characterization fails to tell us anything about the intrinsic nature of the relata that stand in these causal relations-

\begin{abstract}
Reference to the proton is fixed as the thing that causes interactions of a certain kind, that combines in certain ways with other entities, and so on; but what is the thing that is doing the causing and combining? (Chalmers 1996, 153)
\end{abstract}

To answer this question, we need to grasp the intrinsic properties of a proton. But what are those intrinsic properties? What, in general, are intrinsic properties like? With regard to the latter question, Chalmers (along with others ${ }^{15}$ ) points to phenomenal properties.

There is only one class of intrinsic, nonrelational property with which we have any direct familiarity, and this is the class of phenomenal properties. (Chalmers 1996, 153)

If Chalmers is correct that phenomenal properties are the only example of intrinsic properties with which we have any familiarity, then they are the only class of property to

\footnotetext{
${ }^{14}$ This "problem" is really more of a sprawling set of inter-related issues, issues connected to Hume's worry that the primary qualities are not enough to fill in space, Russell's (1927) worry about the physical sciences that leads him to consider neutral monism, and Langton's (1998) recent interpretation of Kant's distinction between the phenomenal and the noumenal.

${ }_{15}$ People who make a similar appeal to phenomenal properties in this context include Foster (1982) and Blackburn (1990).
} 
which we can appeal in solving the problem of matter. But such a "solution" to the problem of matter will strike many as unacceptable, for it seems to lead to Panpsychism. Do we really want to claim that intrinsic properties of a proton are akin to phenomenal blueness, the hurtfulness of pain, and other phenomenal properties?

In an effort to avoid the specter of Panpsychism in this context, Chalmers (1996) makes the following provocative suggestion.

\footnotetext{
Perhaps we might take experience itself as a fundamental feature of the world, alongside spacetime, spin, charge, and the like. That is, certain phenomenal properties will have to be taken as basic properties. Alternatively, perhaps there is some other class of novel fundamental properties from which phenomenal properties are derived... We might call these properties protophenomenal properties, as they are not themselves phenomenal but together they can yield the phenomenal. $(126-127, \text { his emphasis })^{16}$
}

Notice that the second possibility, described by Chalmers above, does not entail Panpsychism, for if phenomenal properties are derived from more basic protophenomenal properties, then the intrinsic properties of material objects could be protophenomenal properties and not phenomenal properties. ${ }^{17}$

Although Chalmers expresses sympathy for the second possibility in several articles, the question of which of these Dualist positions is superior - the one where

\footnotetext{
${ }^{16}$ For additional discussion of this idea, see Chalmers 1996, 153-155 and 298-299. The question of whether phenomenal properties are fundamental (non-physical) properties or are derived from more fundamental (non-physical) protophenomenal properties is a question that Chalmers also raises in his 1995 and 2002.

${ }^{17}$ The second proposal leads to the question of how protophenomenal properties "combine" into phenomenal properties. For helpful discussions of the "combination" problem, see Goff 2009 and Chalmers unpublished.
} 
phenomenal properties are fundamental non-physical properties or the one where they are derived from more fundamental, non-physical protophenomenal properties - is irrelevant for our purposes. What's important for us, rather, is that in discussing these two Dualist solutions to the problem of matter, Chalmers acts as though both are live possibilitieshe acts as though both accounts of phenomenal properties are consistent with what we know about phenomenal properties, including what we know about them through introspection. ${ }^{18}$ For what it's worth, I think he's right about this; I think you can't rule out the possibility that phenomenal properties are derived from protophenomenal properties (or that they are fundamental properties) simply on the basis of introspection. Indeed, I suspect that most people would accept the claim that introspection does not speak to the question of the status of phenomenal properties as fundamental or nonfundamental properties of the universe.

I believe this plausible claim about introspection leads to a potential problem for Chalmers, for it suggests that the primary and secondary intensions of phenomenal concepts do not coincide. More specifically, I think the claim that phenomenal properties could be, for all we know, either fundamental properties or derived from more

\footnotetext{
${ }^{18}$ An alternative reading is that Chalmers takes both positions about phenomenal properties (the position that they are fundamental and the position that they are derived from more basic protophenomenal properties) to be live possibilities not in the sense that introspection is neutral on this issue, but instead in the sense that he (Chalmers) is a fallible being and therefore his preferred theory of phenomenal properties could end up being false. (I want to thank an anonymous referee for introducing this rival reading.) If this were Chalmers' position, however, one would expect him to say something about which of these two possibilities concerning phenomenal properties is actually favored by introspection. But Chalmers never seems to comment on this issue. I take his (Chalmers') silence on this matter as evidence for my reading of the situation, a reading where Chalmers is acting as though introspection is silent or neutral on the issue of whether phenomenal properties are fundamental or are derived from more fundamental, protophenomenal properties.
} 
fundamental protophenomenal properties can be used as a premise in an argument for thinking that the primary and secondary intensions of phenomenal concepts do not coincide in all worlds. In the next section, I construct this argument.

IV. An Argument for the Non-Coincidence of the Primary and Secondary Intensions of Phenomenal Concepts

Before building this argument, I need to do some terminological ground clearing. A property is "fundamental" or "basic" if it is among a collection of properties that serve as a minimal supervenience base for the rest of reality. ${ }^{19}$ When he floats the possibility that phenomenal properties supervene upon (fundamental) protophenomenal properties, Chalmers is floating the possibility that the former logically supervene upon the latter. Given how Chalmers $(1996,36-41)$ understands the notion of logical supervenience, it's safe to say that if phenomenal properties supervene upon protophenomenal properties, then "all there is" to a given phenomenal property are the protophenomenal properties it supervenes upon. To borrow an expression from Armstrong $(1997,12)$, once the relevant protophenomenal properties are in place, the phenomenal properties are "an ontological free lunch".

To make progress in understanding the nature of the relation between phenomenal properties and protophenomenal properties, I think it's useful to consider the way that David Armstrong $(1978,1997)$ understands the relation between complex properties and the more fundamental properties that compose them. According to Armstrong, a

\footnotetext{
${ }^{19}$ For another sense in which properties could be claimed to be "fundamental" - a sense focused on capturing the causal powers of (and objective similarities between) objects, see Schaffer 2004. And for an intriguing discussion of whether there even is a "fundamental" level of reality (in the sense that concerns us), see Schaffer 2003.
} 
complex property is either an assemblage of more fundamental properties (the result being a "conjunctive property") or an assemblage of more fundamental properties plus some relations (the result being a "structural property"). In either case, the complex property in question logically supervenes upon these other properties/relations; the former is nothing "above and beyond" the latter. Indeed, Armstrong $(1978,36-39)$ says that the latter are "parts" of the former. This does not make complex properties any less real than the more fundamental properties/relations that are their constituents, nor does it "reduce" the former to the latter. After all, a complex property might involve a "synergism" of the causal powers of the properties that compose it and, as a result, convey an overall causal power that is either less or more than the sum of the powers that would be conveyed by its individual parts considered in isolation of one another. ${ }^{20}$

I think there are some striking parallels between "Armstrongian" complex/fundamental properties and "Chalmersian" phenomenal/protophenomenal properties. ${ }^{21}$ To start with, we've seen that phenomenal properties are an ontological free lunch given the protophenomenal properties they supervene upon. In this way, they are similar to Armstrongian complex properties that are an ontological free lunch given the fundamental properties they supervene upon. What's more, Chalmers $(1996,127)$ says that the relation between a phenomenal property and its protophenomenal properties is akin to the relation between temperature and more fundamental physical properties.

\footnotetext{
${ }^{20}$ For additional discussion of this point, see Armstrong 1997, 32.

${ }^{21}$ More carefully, there are parallels between what Armstrong says about complex and fundamental properties and what Chalmers says about the most fundamental phenomenal properties and protophenomenal properties. (The phenomenal property of seeing a red square next to a yellow circle, for instance, contains more fundamental phenomenal properties as parts. But this is not the relation that Chalmers is addressing in his discussion of phenomenal properties deriving from protophenomenal properties.)
} 
Given that the latter is plausibly understood in terms of a relation between a complex property and its constituent properties/relations, it is reasonable to assume that the former relation should be understood in the same terms.

Yet another similarity is that Chalmers $(1996,154)$ claims that no single protophenomenal property entails a phenomenal property. Likewise, no single fundamental property entails a complex property under Armstrong's account. To be fair, Chalmers does not assume that phenomenal properties are the result of simply summing together the relevant protophenomenal properties; he allows that phenomenal properties might be determined more "holistically" than this. (See, for instance, Chalmers 1996, 299.) But this is also consistent with Armstrong's account of complex properties. Recall that Armstrong does not maintain that all complex properties are merely sums of other properties; some complex properties—structural properties—also include relations as constituents.

Finally, recall that Armstrong allows that an assemblage of (more fundamental) properties could result in a complex property that conveys causal powers that are less or more than the sum of the powers that would be conveyed by its individual parts considered in isolation of one another. In a similar vein, Chalmers $(1996,154)$ maintains that an assemblage of protophenomenal properties results in a complex property that has an overall introspectible character that the relevant individual protophenomenal properties, considered in isolation of one another, lack.

On the basis of these similarities, I'm going to assume that if they are nonfundamental properties, then phenomenal properties are a type of "Armstrongian" complex property. (Later in this section, I will consider way in which Chalmers could 
reject this assumption and the potential costs of his doing so.) This means that if phenomenal properties are derived from non-fundamental properties, then they contain other properties - protophenomenal properties - as constituents (or parts). If, in contrast, they are fundamental properties, then they are simple properties that do not contain other properties as constituents (or parts). As a result, the question of whether phenomenal properties are fundamental or non-fundamental is, among other things, a question about whether phenomenal properties are simple properties or complex properties; it is, among other things, a question about whether they contain other (protophenomenal) properties as proper parts.

The question of whether a given phenomenal property is simple or complex, as I cashed that distinction out above, is a question about its intrinsic nature. ${ }^{22}$ So to occupy the position that he does with regard to the problem of matter- to act as though the question of whether phenomenal properties are fundamental (and therefore simple) or derived (and therefore complex) is a live question - the primary intensions of our phenomenal concepts would need to be neutral on the question of whether their extensions are simple or complex properties. For this to be a live question, the primary intension of a phenomenal concept would need to leave certain epistemic possibilities open; it would need to pick out a simple property in some worlds, while picking out a

${ }^{22}$ Chalmers (1995) allows that there is another sense in which experience is "complex" or "structured"-namely, experiences have such "structural properties" as similarity and difference relations, perceived location, relative intensity, and geometric structure. According to Chalmers, these structural properties do not exhaust the character of our conscious experiences, for they do not tell us anything about the intrinsic nature of the phenomenal properties of our experience. It is the latter that I am talking about when I describe phenomenal properties as being either simple or complex-either the intrinsic nature of these properties is simple (in the case that they are fundamental) or complex (in the case that they contain protophenomenal properties as parts). 
complex property composed of protophenomenal properties in other worlds. As a result, the primary and secondary intensions of that concept would not coincide.

Let's construct this line of reasoning - including the key assumption that if they are non-fundamental, then phenomenal properties are a type of "Armstrongian" complex property—into an explicit argument.

1) Introspection does not settle the question of whether phenomenal properties are fundamental or derived from more fundamental protophenomenal properties. (This premise is seemingly endorsed by Chalmers in his discussion of the problem of matter.)

2) If phenomenal properties are fundamental properties, then they are simple properties. (This premise is true given the standard way of understanding "fundamental" properties.)

3) If phenomenal properties are derived from protophenomenal properties, then they are Armstrongian complex properties that contain protophenomenal properties as proper parts. (I argued for this assumption on the basis of the parallels between how Chalmers describes the relation between phenomenal and protophenomenal properties and how Armstrong describes the relation between complex and the more fundamental properties that compose them.)

4) Introspection alone does not settle the question of whether phenomenal properties are simple properties or complex properties; it does not settle the question of whether phenomenal properties have proper parts. (This claim follows from 1, 2, and 3.) 
5) If introspection does not settle the question of whether phenomenal properties are simple properties or complex properties, then our phenomenal concepts do not rule out all the epistemic possibilities regarding phenomenal properties.

6) If phenomenal concepts do not rule out all the epistemic possibilities regarding phenomenal properties, then the primary and secondary intensions of phenomenal concepts do not coincide in all worlds. (In virtue of not ruling out all of the epistemic possibilities regarding phenomenal properties (apart from the actually obtaining one), the primary intensions of phenomenal concepts would yield different extensions in different worlds. But since they are a natural kind concept, phenomenal concepts have "rigidified" secondary intensions that would yield the same extension in all worlds. This means there will be worlds where the primary and secondary intensions of phenomenal concepts fail to converge upon the same extension.)

Conclusion: The primary and secondary intensions of phenomenal concepts do not coincide in all worlds.

This argument places pressure on Chalmers and anybody else who claims both a) that introspection does not reveal whether phenomenal properties are fundamental or derived from more basic protophenomenal properties and b) that the primary and secondary intensions of phenomenal concepts coincide in all worlds. If they accept my argument, Dualists would need reject one of the previous claims: they would need to reject the claim that introspection does not reveal whether phenomenal properties are fundamental 
or derived from more basic protophenomenal properties or they would need to reject the claim that the primary and secondary intensions of phenomenal concepts coincide in all worlds. Either choice comes with a substantial cost for Dualists: the first choice involves denying a plausible claim about the limits of introspection, while the second choice makes it impossible for Dualists to make the kind of objection they often make against PCS.

A more aggressive strategy for the Dualist would be to retain both of the previous claims and instead challenge some aspect my argument. Interestingly, in a draft of a paper, we can find a suggestion from Chalmers that promises to do just that. ${ }^{23}$ In the paper in question - a draft of forthcoming paper titled "The Combination Problem for Panpsychism"-Chalmers makes the following comment.

\begin{abstract}
One can distinguish the nature of a phenomenal property from the grounds (or realizers or constituters) of an instance of that property. It is a familiar point that a single property can be multiply realized by different grounds in different instances, and it is not clear why the same should not also apply to phenomenal properties. It is then coherent to hold that the nature of a phenomenal property is revealed by introspection although the grounds of a specific instance are not. (12-13)
\end{abstract}

An analogy may be helpful in understanding this proposal. Suppose, as many have thought, that fragility is a multiply realizable higher-level property. One might argue that it's possible to grasp the essence of fragility, qua higher-level property, without necessarily grasping the essence of the various lower-order properties that "ground" or

\footnotetext{
${ }^{23}$ I want to thank both an anonymous referee for pointing me to this paper and David Chalmers for granting me permission to discuss it here.
} 
"realize" or "constitute" fragility in the various situations where it is instantiated.

Similarly, if phenomenal properties were multiply realizable higher-level properties, then perhaps it's possible that introspection can eliminate all the relevant epistemic possibilities (except for the one that actually obtains) regarding those higher-level properties without revealing the essence of the various lower-order properties that ground/realize/constitute them.

This idea challenges my argument because I assumed that phenomenal properties were identical to what Chalmers is calling their "grounds" or "realizers" or "constituters". That is, I assumed that if phenomenal properties were "derived" from protophenomenal properties, then the phenomenal properties themselves would contain those protophenomenal properties as proper parts. (This assumption is embodied in premise 3 of my argument.) If phenomenal properties instead depend upon but are distinct from their grounds/realizers/constituters, then the fact that introspection doesn't tell us whether the grounds/realizers/constituters of a phenomenal property includes protophenomenal properties does not mean that introspection fails to eliminate all the epistemic possibilities (save the actually obtaining one) with regard to the phenomenal property itself. To put the basic idea another way: what the phenomenal property is like is one thing, what it depends upon/is realized by/constituted by is another.

Chalmers' suggestion raises significant questions, questions that need to be answered before we can evaluate the viability of the suggestion and whether it provides a legitimate threat to my argument. Although the basic idea that higher-level properties can be "realized" (or "grounded", or "constituted", etc.) by, while being distinct from, various lower-level properties was once largely unchallenged in the philosophy of mind 
and metaphysics more generally, in recent years it has fallen under scrutiny and is no longer taken to be a problem-free notion. ${ }^{24}$ As a result of this shift, those who are serious about invoking the notion of "realization" (or "grounding", or "constitution", etc.) need to 1) give a positive account of that relation-i.e. a positive account of what, precisely, needs to be true of two property instances in order for one to "realize" the other - and 2) show that their account of the relation can deliver the goods with regard to relevant desiderata. For example, someone who is working on mental causation would need to 1) state what needs to be true of two property instances in order for one to "realize" the other, and 2) show that her account of how the physical realizes (or grounds, or constitutes, etc.) the mental accommodates the causal efficacy of mental properties.

With this in mind, the first thing to note about Chalmers' suggestion that phenomenal properties are realized by, but distinct from, their grounds is that he doesn't give us an account of the realization relation. Since Chalmers isn't seriously pursuing this idea in the paper in question — he's merely introducing it — we shouldn't fault him for not offering an account of the realization relation. But we also shouldn't automatically assume, in absence of additional argument, that there is an account of the realization relation that will give Chalmers what he needs in making this claim about phenomenal properties. As I said above, the times have changed on this front and we can no longer assume that the realization relation, in the form that Chalmers needs it, is a problem-free notion.

${ }^{24}$ Jaegwon Kim's work has been especially important on this front; see, for instance, Kim 1998. For a nice review of the general skepticism surrounding the notions of higher-level properties and the relation of realization/grounding/constitution, see Heil 2003. 
Could Chalmers simply appropriate an extant account of the realization relation? I'm not sure he can. The idea of phenomenal properties being realized by (but distinct from) protophenomenal properties does not fit well with some of the more popular accounts of the realization relation. It does not fit well, for instance, with functionalist accounts where the realization relation is the result of intrinsic properties and the laws of nature giving rise to various functional/relational properties. Nor does it fit well with Sydney Shoemaker's recent (2007) account where the realization relation is the result of one property's causal powers being a proper subset of the causal powers of another property. ${ }^{25}$ Of course, this doesn't establish that there is no extant account of the realization relation that Chalmers could co-opt in making his claim. But it does show that we can't just assume that there is an account of the realization relation already out there that will give Chalmers everything he needs in making the claims about phenomenal properties that he does.

Finally, whatever account of the realization relation that Chalmers might adopt (or develop) would need to accommodate the idea that phenomenal properties can be realized by simple (fundamental) properties in some worlds and by complex (non-fundamental) properties in other worlds. Notice just how large of the metaphysical difference this is between the various lower-level properties that are supposed to form the realization base for phenomenal properties. It is, for instance, a metaphysical difference that is much larger than that which is found between the various molecular structures that (supposedly) realize fragility. Of course, I don't want to claim that it's impossible for a

\footnotetext{
${ }^{25}$ To my knowledge, Chalmers has not explicitly discussed the relation between the causal powers of phenomenal properties and the causal powers of the protophenomenal properties that realize them.
} 
higher-level property to have a realization base of lower-level properties that are this different from one another; I don't want to argue that it's impossible for phenomenal properties to have such deep metaphysical differences between their realizers. But I think the observation of the extent of metaphysical difference between the (supposed) realizers of phenomenal properties reinforces the need for a positive account of realization, an account that explains how, precisely, such extremely different properties—some simple/fundamental, some complex/non-fundamental—could realize one and the same phenomenal property.

In summary, I think we need more details before we can properly evaluate Chalmers' suggestion that phenomenal properties are realized by, but distinct from, their grounds. We need a positive account of the realization relation (or the grounding relation, or the constitution relation, etc.) that is supposed to obtain between phenomenal properties that their realizers before we can ultimately determine whether this idea is viable or whether it creates more philosophical trouble than it's worth. In absence of these details about the realization relation, I am going to conclude Chalmers' suggestion does not provide a legitimate threat to the argument I developed in this section. In short, until someone provides a viable account of the realization relation supposedly obtaining between phenomenal properties and their protophenomenal grounds, the argument I've developed in this section stands and places the ball in the court of the Dualist.

\section{Conclusion}

Using a claim seemingly endorsed by Chalmers in his discussion of the problem of matter and a couple of additional, independently plausible claims, I constructed a relatively 
simple argument for thinking that the primary and secondary intensions of phenomenal concepts do not coincide in all worlds. Since I believe other Dualists are likely to agree with Chalmers that introspection does not settle the question of whether phenomenal properties are simple or are derived from protophenomenal properties, I think my argument will apply to them as well. This argument shows that they—-the Dualists just described - are committed to an idea that, when combined with a couple of other relatively simple premises, implies that the primary and secondary intensions of phenomenal concepts do not coincide.

The (supposed) coincidence of the primary and secondary intensions of phenomenal concepts was the main (introspection-based) complaint against Levin's version and my version of PCS. (Recall that our versions of PCS concede that Loar's account makes the contents of phenomenal concepts too thin and attempt to make those contents more substantial while retaining the idea that these contents contain demonstrative elements.) Once the Dualist allows for the possibility that such properties have a "hidden backside" — once he or she concedes that the primary intensions of phenomenal concepts are not epistemically rigid — this complaint against Levin's version and my version of PCS falls by the wayside and the dialectical situation shifts to our favor.

\section{REFERENCES}

Alter, T. and Walter, S. (eds.) 2007, Phenomenal Concepts and Phenomenal Knowledge, Oxford: Oxford University Press.

\footnotetext{
* I would like to thank Brendan O'Sullivan and several anonymous referees from dialectica for extensive and helpful comments.
} 
Armstrong, D. M. 1968, A Materialist Theory of the Mind, London: Routledge \& Kegan Paul Ltd.

Armstrong, D. M. 1978, Universals and Scientific Realism, Volume II, Cambridge: Cambridge University Press.

Armstrong, D. M. 1997, A World of States of Affairs, Cambridge: Cambridge University Press.

BlackBurn, S. 1990, "Filling in Space”, Analysis 50, pp. 62-65.

Chalmers, D. 1995, "Facing up to the Problem of Consciousness", Journal of Consciousness Studies 2, pp. 200-219.

Chalmers, D. 1996, The Conscious Mind, Oxford: Oxford University Press.

Chalmers, D. 2002, “Consciousness and Its Place in Nature”, in: S. Stich and T. Warfield, eds., Blackwell Guide to the Philosophy of Mind, Malden: Blackwell Publishing, pp. 102-142.

Chalmers, D. 2003, “The Content and Epistemology of Phenomenal Belief”, in: Q. Smith and A. Jokic, eds., Consciousness: New Philosophical Perspectives, Oxford: Oxford University Press, pp. 220-272.

Chalmers, D. 2007, "Phenomenal Concepts and the Explanatory Gap", in: T. Alter and S. Walter, eds., Phenomenal Concepts and Phenomenal Knowledge, Oxford: Oxford University Press, pp. 167-194.

Chalmers, D. 2010, “The Two-Dimensional Argument Against Materialism”, in: D. Chalmers, The Character of Consciousness, Oxford: Oxford University Press, pp. 141-205.

Chalmers, D. 2012, Constructing the World, Oxford: Oxford University Press.

Chalmers, D. unpublished manuscript, "The Combination Problem for PanPyschism", available at Chalmers' website: http://consc.net/chalmers/

Foster, J. 1982, The Case for Idealism, London: Routledge Press.

GofF, P. 2009, “Why Panpsychism doesn't Help Us Explain Consciousness”, Dialectica 63 (2), pp. 289-311.

HeIL, J. 2003, From an Ontological Point of View, Oxford: Oxford University Press.

JACKSON, F. 1982, “Epiphenomenal Qualia”, Philosophical Quarterly 32, pp. 127-136.

KIM, J. 1998, Mind in a Physical World, Cambridge, MA: The MIT Press.

KRIPKE, S. 1980, Naming and Necessity, Cambridge, MA: Harvard University Press. 
LAngton, R. 1998, Kantian Humility: Our Ignorance of Things in Themselves, Oxford: Oxford University Press.

LEVIN, J. 2002, "Is Conceptual Analysis Needed for the Reduction of Qualitative States?”, Philosophy and Phenomenological Research 64, pp. 571-591.

LeVIN, J. 2007, “What Is a Phenomenal Concept?”, in: T. Alter and S. Walter, eds., Phenomenal Concepts and Phenomenal Knowledge, Oxford: Oxford University Press, pp. 87-110.

LeVINE, J. 1983, "Materialism and Qualia: The Explanatory Gap", Pacific Philosophical Quarterly 64, pp. 354-361.

Levine, J. 2001, Purple Haze, Oxford: Oxford University Press.

LoAr, B. 1990, "Phenomenal States", in: J. Tomberlin, ed., Philosophical Perspectives 4, Northridge: Ridgeview, pp. 81-108.

PAPINEAU, D. 2002, Thinking about Consciousness, Oxford: Oxford University Press.

Russell, B. 1927, The Analysis of Matter, London: Kegan Paul.

SCHAFFER, J. 2003, “Is There a Fundamental Level?”, Nous 37 (3), pp. 498-517

Schaffer, J. 2004, “Two Conceptions of Spares Properties”, Pacific Philosophical Quarterly 85, pp. 92-102.

Schroer, R. 2010, “Where's the Beef? Phenomenal Concepts as Both Demonstrative and Substantial", The Australasian Journal of Philosophy 88 (3), pp. 505-522.

Shoemaker, S. 2007, Physical Realization, Oxford: Oxford University Press.

StAlnAKer, R. 2002, "What is it Like to be a Zombie?", in: T. Gendler and J. Hawthorne, eds., Conceivability and Possibility, Oxford: Oxford University Press, pp. 385-400.

Stoljar, D. 2005, "Physicalism and Phenomenal Concepts", Mind and Language 20, pp. 469-494. 